\title{
PERANCANGAN SISTEM INFORMASI PENJUALAN BERBASIS E-COMMERCE STUDI KASUS TOKO KUN JAKARTA
}

\author{
Sutri Handayani \\ sutri.sfx@bsi.ac.id \\ STMIK NUSA MANDIRI JAKARTA
}

\begin{abstract}
Abstrak
Teknologi informasi sangatlah berpengaruh untuk kemajuan suatu usaha. Berbagai macam cara dilakukan untuk mempromosikan usaha yang dimiliki, salah satunya dengan menggunakan website ecommerce. E-commerce adalah suatu kegiatan jual beli yang dilakukan secara online melalui situs atau website. Pada studi kasus Toko KUN, permasalahan yang sering dihadapi adalah media promosi hanya menggunakan spanduk, penjualan masih sebatas offline, penyimpanan data dan pencetakan laporan masih berupa pencatatan dalam bentuk arsip. Tujuan dari penelitian adalah memberi solusi pemecahan masalah-masalah yang ada dengan merancang sebuah sistem informasi penjualan berbasis ecommerce. Hasil dan kesimpulan dari penelitian ini adalah website penjualan berbasis ecommerce dapat dijadikan sebagai media promosi, mempermudah proses penjualan yang dilakukan secara online, serta dapat mempermudah dalam pengolahan data dan pencetakan laporan yang tidak lagi memerlukan pencatatan dalam bentuk arsip.
\end{abstract}

Kata kunci: Sistem Informasi, E-commerce,Website

\begin{abstract}
Information technology is very influential for the progress of a business. Various ways are done to promote the business owned, one of them by using ecommerce website. E-commerce is a buying and selling activity conducted online through the website or website. In KUN Toko case study case, the problem that often faced is the promotion media using only banners, the sale is still limited to offline, data storage and printing report is still in the form of records in the form of archives. The purpose of the research is to provide solutions to solve existing problems by designing an ecommerce-based sales information system. The results and conclusions of this research is ecommerce-based sales website can be used as a media campaign, simplify the process of selling done online, and can simplify the data processing and printing reports that no longer require recording in the form of archives.
\end{abstract}

Keywords: Information Systems, E-commerce, Website

\section{Pendahuluan}

"Inter Connection Networking (internet)" adalah jaringan komputer yang menghubungkan antar jaringan secara global, internet dapat juga disebut jaringan dalam suatu satu jaringan yang luas [1]. Internet juga menggunakan protocol komunikasi yaitu TCP/IP (Transmission Control Protocol /Internet Protocol). Ecommerce didefenisikan sebagai transaksi perdagangan yang dimungkinkan secara digital antar organisasi dengan organisasi atau dengan individula serta antar individual dengan individual. Toko Kun adalah suatu usaha yang bergerak dibidang penjualan pakaian muslimah. Masalah yang dihadapi oleh toko kun adalah sistem penjualan yang masih dilakukan secara offline, dimana konsumen harus datang langsung ketoko jika ingin membeli barang. Kurang luasnya jangkauan promosi yang yang digunakan oleh toko kun masih menggunakan media spanduk didepan toko. Penyimpanan data dan pencetakan laporan masih menggunakan pencatatan kedalam arsip. Batasan masalah pada penelitian ini meliputi transaksi penjualan berbasis ecommerce, promosi melalui media website, penyimpanan data yang akan disimpan kedalam database sehingga mempermudah ketika akan mencetak laporan. Tujuan penelitian ini adalah menghasilkan sistem informasi penjualan berbasis ecommerce yang nantinya dapat membantu dalam pengolahan data, promosi dan transaksi yang dilakukan melalui media website ecommerce.

\section{Landasan Teori}

\subsection{E-commerce}

Ecommerce adalah suatu perangkat teknologi yang dinamis,meliputi aplikasi dan pross bisnis yang menghubungkan perusahaan,konsumen dan suatu komunitas melalui transaksi elektronik, yang menyelenggarakan pertukaran elektronik barang [2]. 


\subsection{Website}

"Word Wide Web atau Waring Wera Wanua, disingkat sebagai WWW" adalah suatu ruang informasi yang dipakai oleh pengenal global yang disebut Pengidentifikasi Sumber Seragam untuk mengenal pasti sumber daya berguna. WWW sering dianggap sama dengan internet secara keseluruhan, walaupun sebenarnya ia hanyalah bagian daripada internet [3].

\subsection{ERD (Entity Relationship Diagram)}

Menurut [4], ERD (Entity Relationship Diagram) adalah dikembangkan berdasarkan teori himpunan dalam bidang matematika". ERD digunakan untuk pemodelan basis data relasional. Sehingga jika penyimpanan basis data menggunakan OODBMS maka perancangan basis data tidak perlu menggunakan $E R D$.

\subsection{UML (Unified Modelling Language)}

UML (Unified Modelling Language) adalah bahasa pemodelan untuk sistem atau perangkat lunak yang berparadigma berorientasi objek. Pemodelan (modelling) sesungguhnya digunakan penyederhanaan permasalahan permasalahan yang kompleks sedemikian rupa sehingga lebih mudah dipelajari dan dipahami. Dalam menganalisa dan merancang suatu basis data dapat digunakan diagram UML (Unified Modelling Language). UML merupakan salah satu tool model untuk merancang pemodelan software yang berbasis object oriented [5].

\section{Metode}

Metode yang digunakan dalam penelitian adalah model waterfall. Menurut [4] menjelaskan bahwa "Model Waterfall adalah model SDLC yang paling sederhana, model ini hanya cocok untuk pengembangan perangkat lunak dengan spesifikasi yang tidak berubah - ubah". Pendekatan SDLC dengan berbagai pekerjaan di suatu tahap diselesaikan terlebih dulu sebelum pekerjaan dilanjutkan ke tahap berikutnya. Aliran SDLC sebagian besar tetap sama, berapa pun jumlah tahapannya.

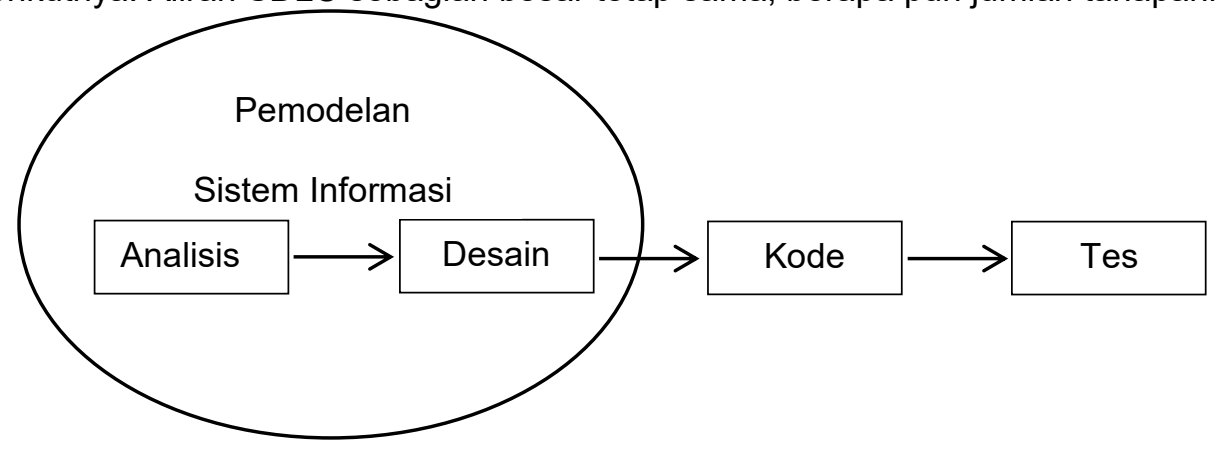

Gambar 1. Ilustrasi Waterfall Model

1). Analisis kebutuhan perangkat lunak (Analysis)

Proses pengumpulan kebutuhan dilakukan secara intensif untuk menspesifikasikan perangkat lunak agar dapat dipahami perangkat lunak seperti apa yang dibutuhkan oleh user. Spesifikasi kebutuhan perangkat lunak tahap ini perlu untuk didokumentasikan.

2). Desain (Design)

Desain perangkat lunak adalah proses multi langkah yang fokus pada desain pembuatan program perangkat lunak, representasi antarmuka, dan prosedur pengkodean. Tahap ini menstranslasi kebutuhan perangkat lunak, dari tahap analisis kebutuhan representasi desain agar dapat diimplementasikan menjadi program pada tahap selanjutnya. Desain perangkat lunak, dari tahap analisis kebutuhan representasi desain agar dapat diimplementasikan menjadi program pada tahap selanjutnya. Desain perangkat lunak yang dihasilkan pada tahap ini juga perlu didokumentasikan.

3). Pembuatan kode program (Code)

Desain harus ditranslasikan ke dalam program perangkat lunak. Hasil dari tahap ini adalah program komputer sesuai dengan desain yang telah dibuat pada tahap desain.

4). Pengujian (Test)

Pengujian fokus pada perangkat lunak secara dari segi lojik dan fungsional dan memastikan bahwa semua bagian sudah diuji. Hal ini dilakukan untuk meminimalisir kesalahan (error) dan memastikan keluaran yang dihasilkan sesuai yang diinginkan. 


\section{Hasil dan Pembahasan}

\subsection{Activity Diagram}

Berikut merupakan gambaran activity diagram dari sistem penjualan online pada toko Kun yang diusulkan :

1. Prosedur Pendaftaran

Pengunjung membuka website toko, pengunjung yang belum mendaftar harus melakukan pendaftaran terlebih dahulu. Pengunjung mengisi form pendaftaran, setelah mengisi form pendaftaran kemudian customer dapat melakukan login dengan user name dan password yang telah dibuat, lalu customer dapat melakukan pemesanan barang.

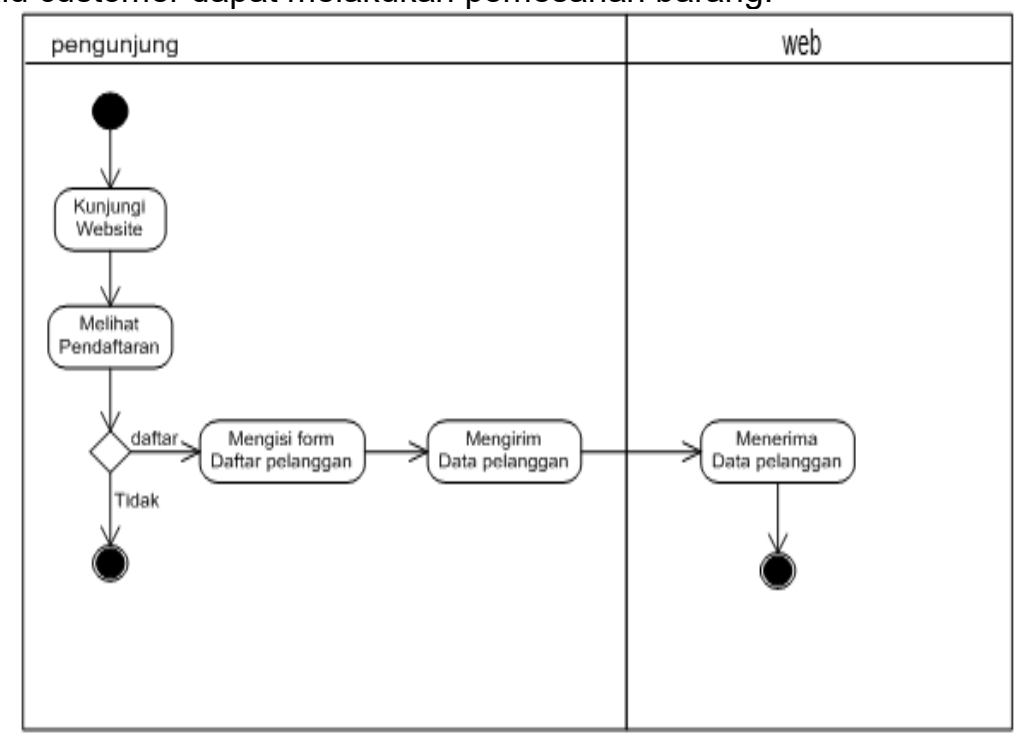

Gambar 2. Activity Diagram Pendaftaran

2. Prosedur Pembayaran

Customer melakukan pembayaran sesuai dengan total biaya yang tertera di faktur, customer melakukan pembayaran dengan cara transfer ke rekening pemilik toko. Setelah melunasi pembayaran, customer melakukan konfirmasi melalui email bahwa telah melunasi pembayaran, setelah admin menerima email dari customer, admin akan mengirimkan balasan konfirmasi ke email customer. Batas waktu pembayaran sampai dengan tiga hari, jika lebih dari tiga hari maka transaksi akan dibatalkan.

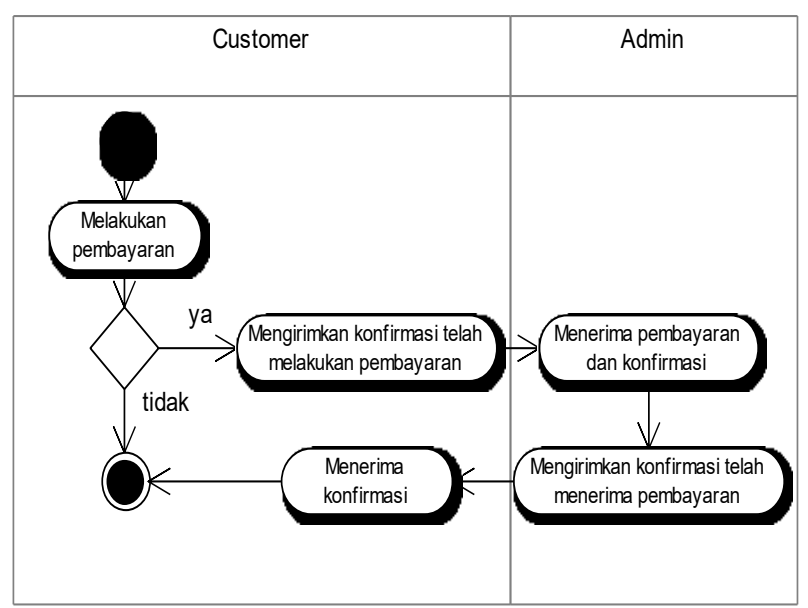

Gambar 3. Activity Diagram Pembayaran

3. Prosedur Pemesanan

Setelah customer berhasil login, maka customer dapat memilih produk yang diinginkan, Untuk memesan produk yang diinginkan pembeli dapat langsung mengklik tombol beli maka produk yang dibeli akan tersimpan ke keranjang belanja. Jika customer ingin memesan produk yang lain maka customer memilih tombol lanjutkan belanja lalu pilih produk yang lainnya. Untuk merubah jumlah produk yang dipesan customer cukup mengklik tombol update. Setelah customer selesai melakukan pemesanan maka customer langsung mengklik tombol selesai belanja maka akan 
tampil form data customer yang harus dilengkapi kembali, jika sudah melengkapi data, pembeli langsung memilih tombol proses lalu tampil faktur penjualan, di faktur penjualan tertera nama barang yang dipesan beserta rincian biaya yang harus dibayar. Setelah data terkirim admin akan mengirimkan data rekening toko ke email cuctomer.

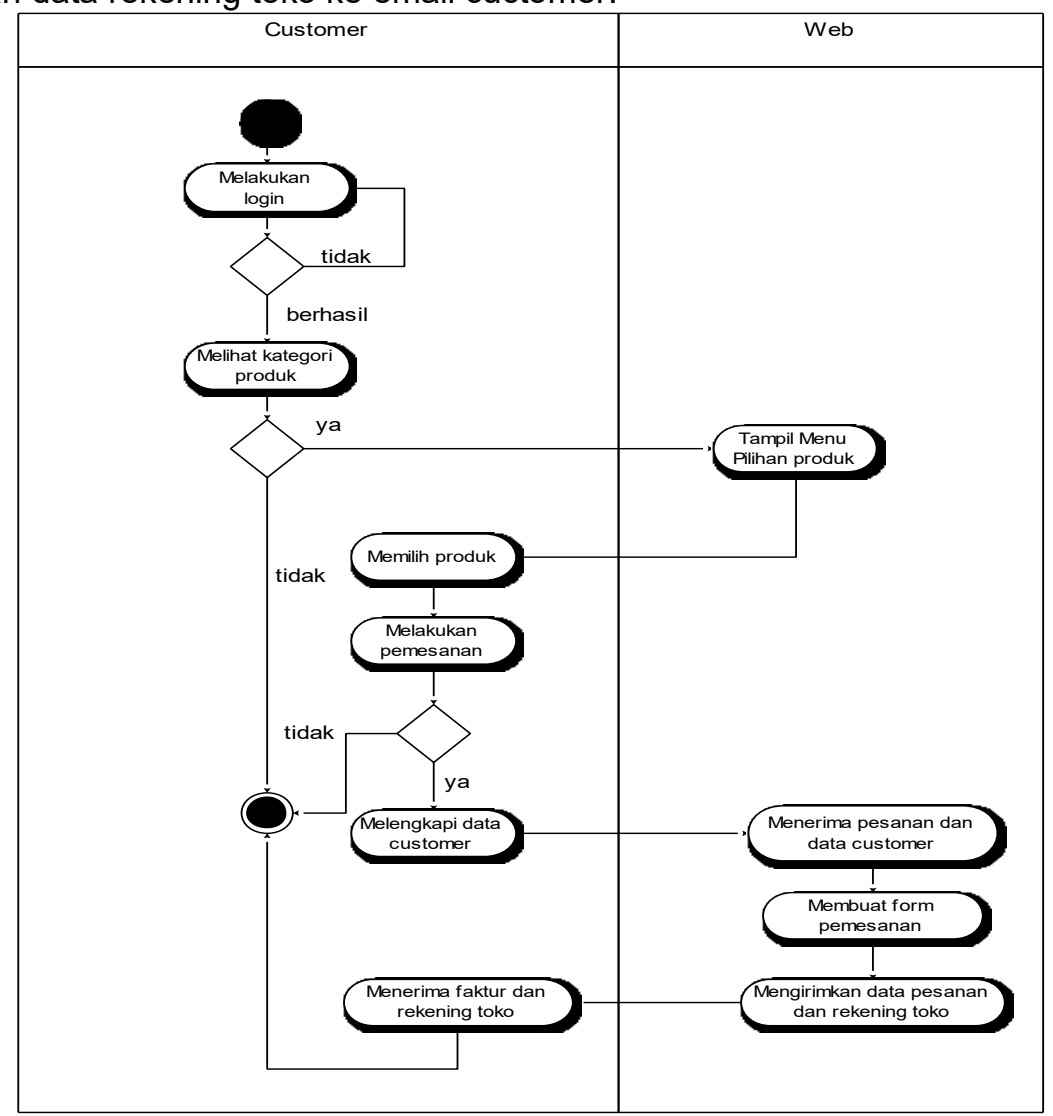

Gambar 4. Activity Diagram Pemesanan

4. Prosedur Laporan

Laporan data pemesanan dan data produk dibuat berdasarkan data pemesanan yang telah tersimpan, laporan data pemesanan dan data produk dicetak oleh bagian admin selanjutnya dilaporkan kepada Pemilik Toko.

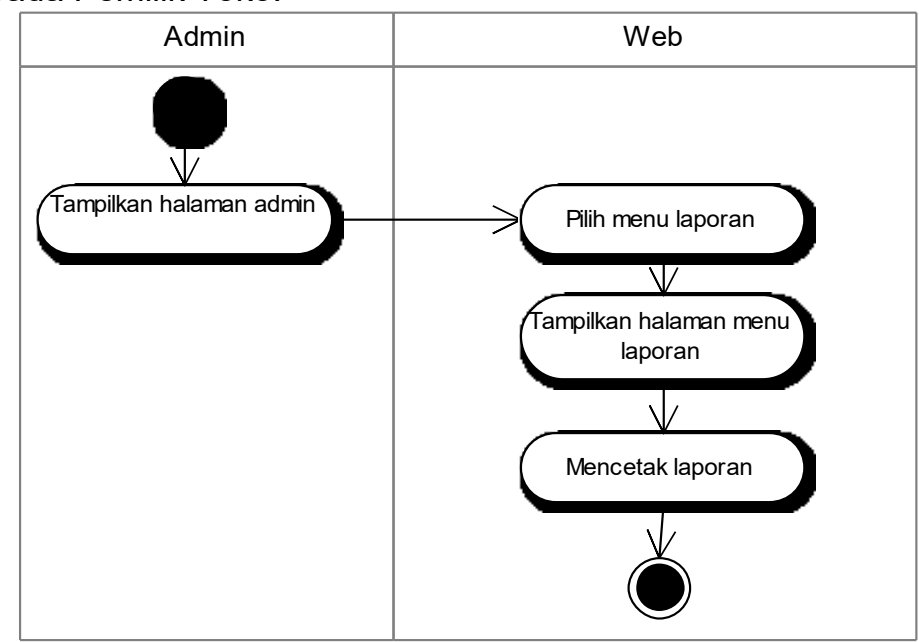

Gambar 5. Activity Diagram Pembuatan Laporan

\subsection{Use case Diagram}

Use case diagram digunakan untuk mendeskripsikan apa yang seharusnya dilakukan oleh sistem. Diagram usecase menyediakan cara mendiskripsikan pandangan eksternal terhadap sistem dan interaksi-interaksinya terhadap dunia luar. Berikut ini merupakan use case diagram dari sistem penjualan barang online pada toko kun yang diusulkan : 
1. Use Case Diagram Home

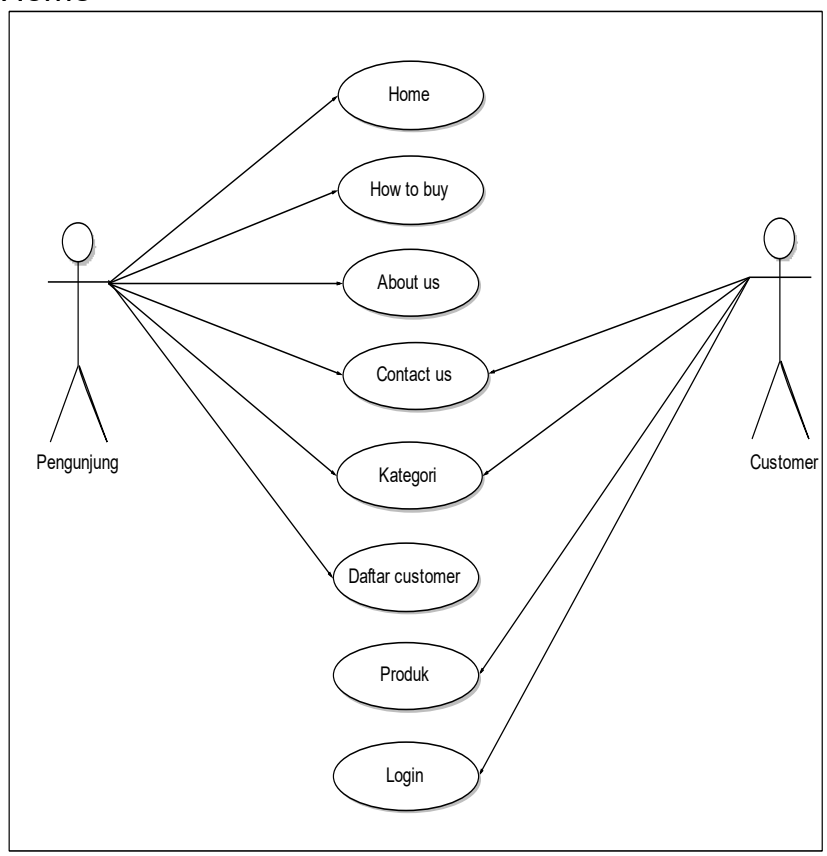

Gambar 6. Use Case Diagram Home

2. Use Case Diagram Pendaftaran

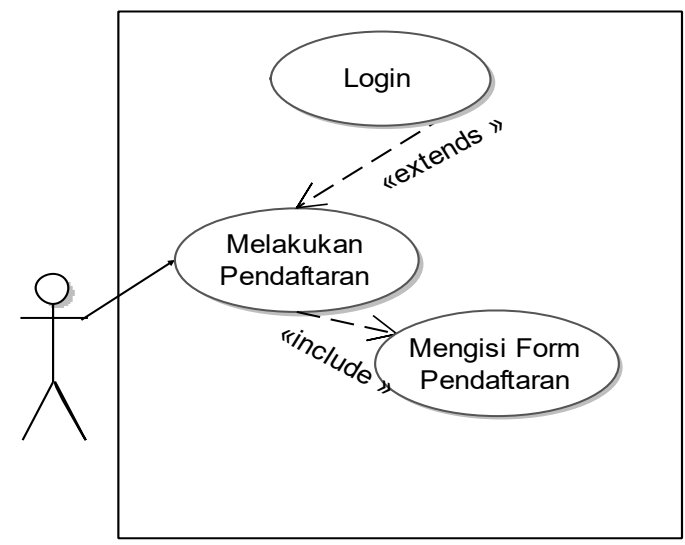

Gambar 7. Use Case Diagram Pendaftaran

3. Use Case Diagram Pemesanan

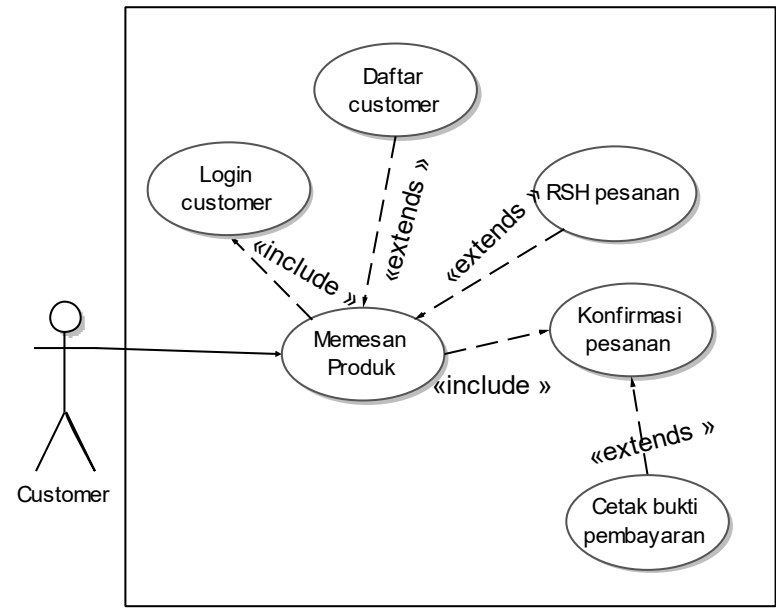

Gambar 8. Use Case Diagram Pemesanan 


\section{ILKOM Jurnal Ilmiah Volume 10 Nomor 2 Agustus 2018}

4. Use Case Diagram Laporan

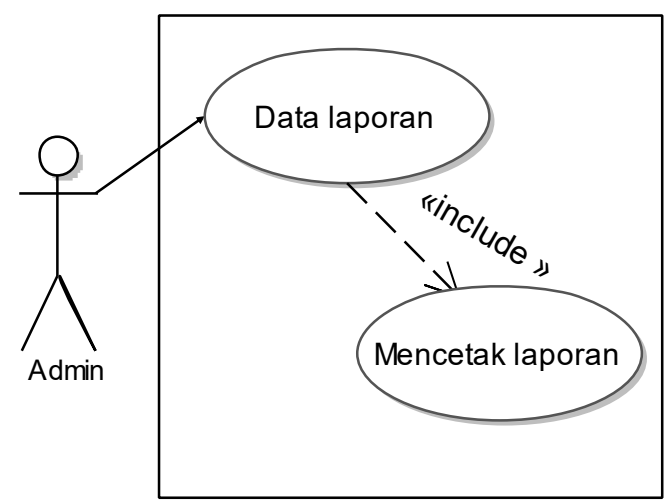

Gambar 9. Use Case Diagram Pembuatan Laporan

\subsection{ERD (Entity Relationship Diagram)}

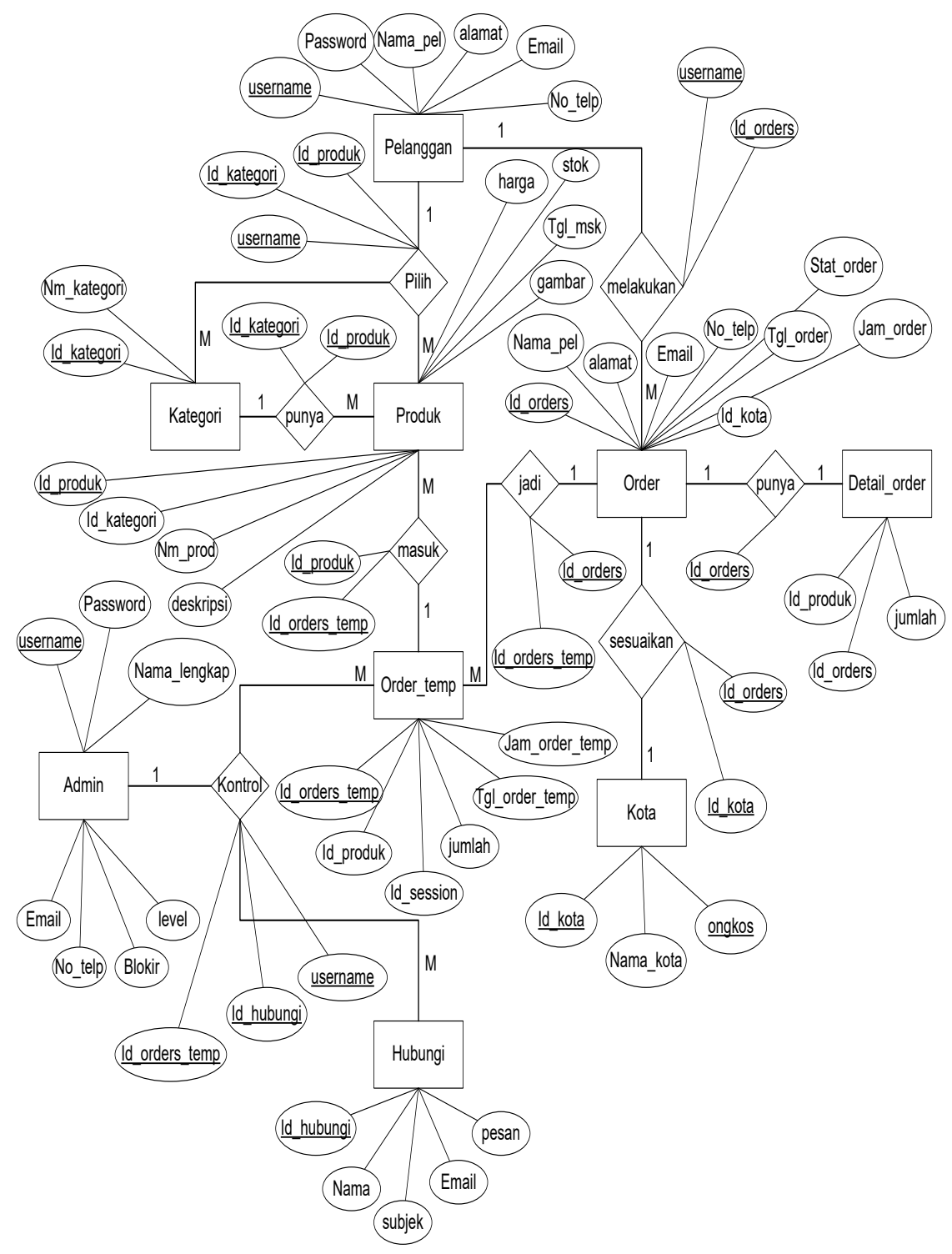

Gambar 10. Entity Relationship Diagram 


\subsection{Rancangan Tampilan}

Berikut merupakan gambaran dari rancangan website Toko Kun:

1. Halaman Home Pengunjung

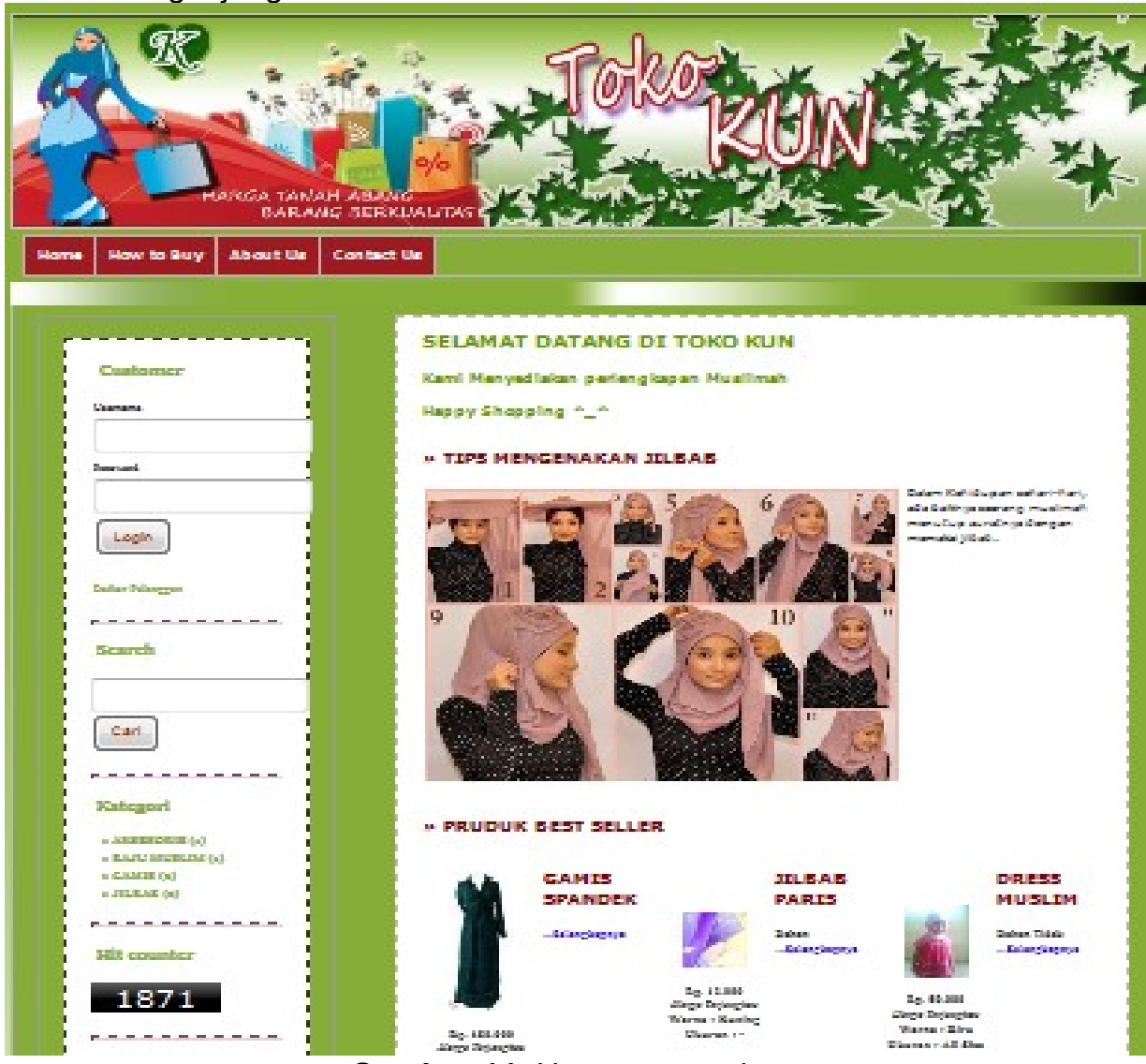

Gambar 11. Home pengunjung

2. Halaman Keranjang Belanja

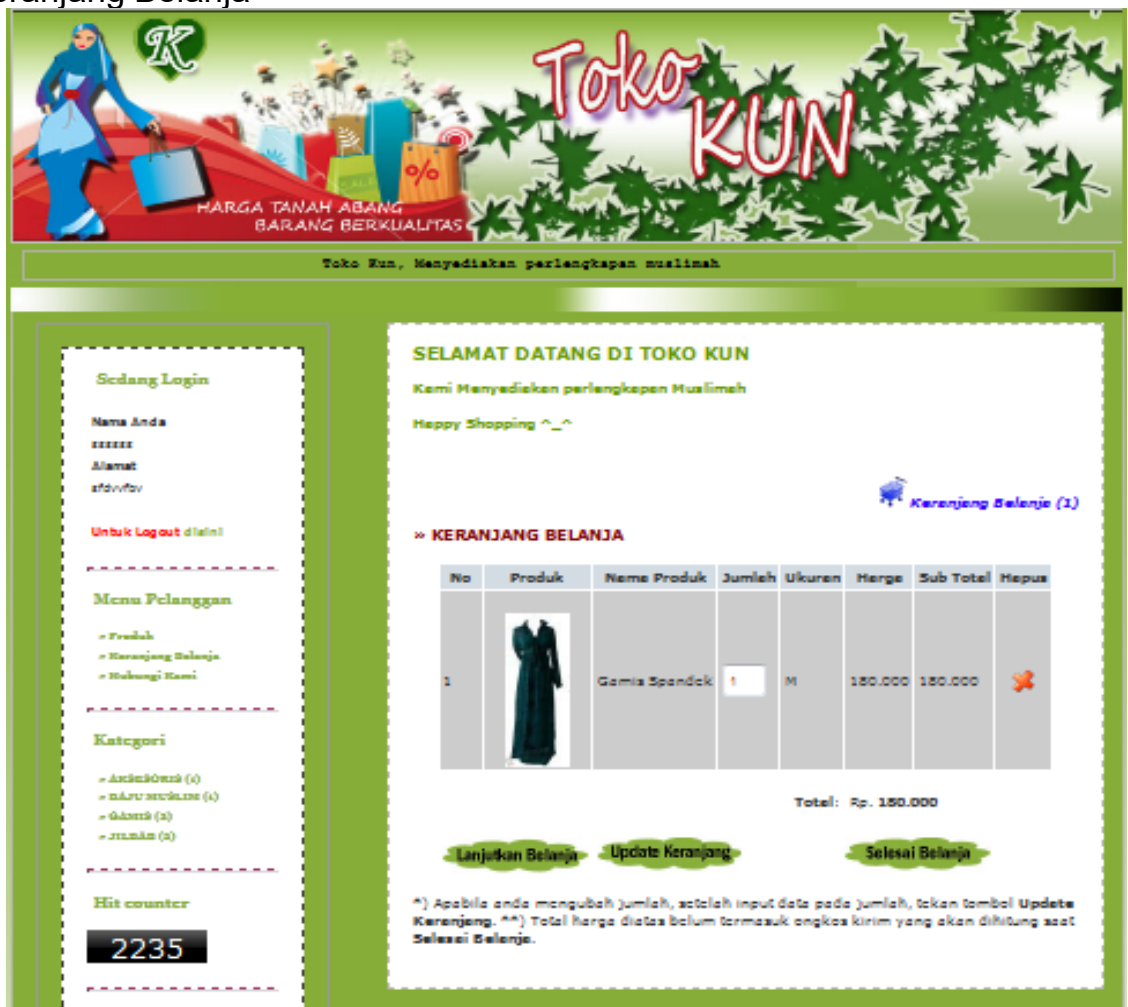

Gambar 12. Rancangan halaman keranjang belanja 


\section{Kesimpulan dan Saran}

\subsection{Kesimpulan}

Dengan adanya sistem informasi penjualan berbasis ecommerce dapat memudahkan konsumen dalam melakukan pemesanan barang secara online, karena konsumen tidak perlu datang langsung ketoko. Mempermudah promosi melalui media website yang jangkauannya lebih luas dibandingkan dengan promosi dengan menggunakan spanduk. Mempermudah dalam penyimpanan data dan pencetakan laporan yang dapat disimpan dan diaksen melalui website

\subsection{Saran}

Menambahkan lebih banyak konten agar tampilan website lebih lebih sempurna. Membackup data-data yang sudah tersimpan agar lebih aman. Melakukan maintenance terhadap website secara berkala.

\section{Daftar Pustaka}

[1] F. A. Sibero, WEB Programming Power Pack. Yogyakarta: Mediakom, 2013.

[2] H. T. Sihotang, "Sistem pakar untuk mendiagnosa penyakit pada tanaman jagung dengan metode bayes," J. Inform. Pelita Nusant., vol. 3, no. 1, 2018.

[3] M. Sandi, Bikin Website Dengan Aplikasi-Aplikasi Gratis. Yogyakarta: Mediakom, 2014.

[4] R. A. M. S. Sukamto, Rekayasa Perangkat Lunak Terstuktur Dan Berorientasi Objek. Bandung: Informatika Bandung, 2013.

[5] J. I. G. W. F. F. L. Efendi, Kamus Istilah Hukum Populer. Jakarta: PRENADAMEDIA GROUP, 2016. 